\title{
A Robust Bias Against Interracial Couples Among White and Black Respondents, Relative to Multiracial Respondents
}

\author{
Allison L. Skinner ${ }^{\dagger}$ \\ James R. Rae \\ Northwestern University \\ University of Massachusetts Amherst
}

${ }^{\dagger}$ Please address correspondence regarding this research to Allison L. Skinner, allisonlskinner@gmail.com.

This manuscript has been accepted for publication at Social Psychological and Personality

Science. This manuscript will go through changes in copy-editing through the

journal's editorial office and thus this version of the article may not reflect the version that is eventually published in the journal. Please cite this paper using the following reference:

Skinner, A.L. \& Rae, J.R. (in press). A Robust Bias Against Interracial Couples Among White and Black Respondents, Relative to Multiracial Respondents. Social Psychological and Personality Science. 


\begin{abstract}
Interracial couples are an understudied but increasingly common social group in the U.S. We used direct and indirect measures to examine implicit and explicit biases (respectively) against interracial couples among samples of: (a) predominantly White (non-Black; $n=1,217$ ), (b) Black ( $n=293$ ), and (c) Multiracial ( $n=284)$ respondents recruited from the U.S. Results provide evidence of implicit and explicit bias against Black-White interracial couples among respondents in the predominantly White Sample and the Black Sample. There was no evidence of such biases among self-identified Multiracial respondents, in fact, they self-reported favoritism for interracial couples. Consistent with psychological theory and our preregistered hypotheses, we found that personal experience with interracial romance and self-reported contact with interracial couples tended to predict lower levels of bias against interracial couples. This research exposes a robust bias against a growing social group (interracial couples) among predominantly White respondents and Black respondents relative to respondents who identify as Multiracial.
\end{abstract} Keywords: Interracial couples, racial bias, implicit bias, explicit bias, Implicit Association Test 


\section{A Robust Bias Against Interracial Couples Among White and Black Respondents, Relative to Multiracial Respondents}

Fifty years ago, the U.S. Supreme Court invalidated remaining state laws enforcing racial segregation in marriage and intimate relationships (Loving v. Virginia, 1967). Since then, interracial marriage has become increasingly common-approximately $15 \%$ of new marriages in 2010 were interracial (Wang, 2012). Romantic relationships between people of different races are also becoming increasingly common on television (Fitzpatrick, 2015), in film (R. L., 2016), and in advertising (Mullins, 2014). In line with these changes, polling data suggests that people in the U.S. are increasingly accepting of interracial marriage (Hayes, 2012). Taken together, it appears that in the U.S. interracial romance has transformed from a criminal offense into an accepted practice in just 50 years.

Despite evidence for the increasing numbers, visibility, and reported acceptance of interracial couples, some evidence suggests that they may still be the targets of bias and discrimination (Skinner \& Hudac, 2017). Psychologists typically differentiate between explicit (i.e., controlled and deliberate) and implicit (i.e., automatically activated) biases (Greenwald \& Banaji, 1995). Explicit biases are typically assessed through self-report (i.e., direct measures), whereas implicit biases are inferred from participants' performance (e.g., response latencies or error rates) on tasks that do not inform respondents to what is being measured (i.e., indirect measures; De Houwer, 2006). Looking at racial biases more generally, national polls indicate that explicit bias against Black people has steeply declined in the U.S., yet evidence suggests that there are still robust implicit anti-Black biases (e.g., Rae, Newheiser, \& Olson, 2015). Given this discrepancy between implicit and explicit racial biases, the current work investigates whether implicit attitudes toward Black-White interracial couples are as positive as the explicit attitudes 
suggested by national polls. We focus on attitudes toward Black-White interracial couples given the historical and ongoing significance of such relationships in the U.S. (Loving v. Virginia, 1967; Newport, 2013).

\section{Theoretical Moderators of Intergroup Bias}

Though there is some evidence that interracial couples elicit a disgust response and tend to be dehumanized (relative to same-race couples) on indirect measures (Skinner \& Hudac, 2017), little work has investigated biases against interracial couples. Thus, in addition to assessing evidence for implicit bias against interracial couples, we also sought to lay a foundation for understanding bias against interracial couples by testing some of the most wellestablished moderators of intergroup biases.

Experience with interracial romance. Several prominent theories posit that people tend to favor groups they belong to over those they do not belong to (Sherif, 1966; Tajfel, 1978; Turner, Hogg, Oakes, Reicher, \& Wetherell, 1987). Thus, we predicted that respondents who were currently engaged in interracial romance (i.e., who are part of an interracial couple) would have more positive attitudes toward interracial couples than respondents with no experience with interracial romance. Moreover, multicultural theorizing indicates that involvement in interracial romantic relationships leads to an identity transformation, in which being a part of an interracial couple becomes part of one's identity (Foeman \& Nance, 1999). Thus, we similarly expected respondents with previous experience with interracial romance (versus respondents with no experience) to hold more favorable attitudes towards interracial couples (for evidence consistent with this prediction, see Lienemann \& Stopp, 2013).

Intergroup contact. Much evidence suggests that contact with outgroup members is associated with reduced explicit bias against them (e.g., Allport, 1954; Pettigrew \& Tropp, 2006; 
Shook \& Fazio, 2008; Turner, Hewstone, \& Voci, 2007). As such, we predicted that contact with interracial couples would be associated with lower levels of both implicit and explicit bias against interracial couples.

Mere exposure. Repeated exposure to a stimulus increases positive attitudes toward that stimulus (Zajonc, 2001), including social stimuli such as faces of outgroup members (Zebrowitz, White, \& Wieneke, 2008). Thus, with respect to interracial couples, one possibility is that increased incidental exposure to interracial couples would reduce bias against them. Consistent with this prediction, Lienemann and Stopp (2013) found that media exposure to interracial couples predicted positive explicit attitudes towards interracial dating among White respondents in the U.S. Yet, there is also evidence that (a) mere exposure can increase disliking towards previously disliked stimuli (Crisp, Hutter, \& Young, 2009; Grush, 1976) and (b) exposure to outgroup members can sometimes be associated with increased prejudice—particularly when outgroup members pose some sort of threat (Rae et al., 2015). Given that interracial couples could represent a form of betrayal of the racial ingroup, exposure to interracial couples could potentially increase bias against them.

\section{Overview of The Current Research}

To investigate implicit and explicit bias against Black-White interracial couples, we collected data from three distinct samples in the U.S., individuals who self-identify as (a) nonBlack (predominately White), (b) Black, and (c) Multiracial. We predicted that both the predominantly White and Black samples would show an implicit bias against interracial couples

(Hypothesis 1). We reasoned that people who self-identify as Multiracial likely have at least two features that may insulate them from bias against interracial couples: flexible and overlapping racial identities (e.g., Daniel, 2002; Gaither et al., 2014)—a factor known to negatively correlate 
with bias (e.g., Roccas \& Brewer, 2002)—and extensive contact with at least one interracial couple, their parents. We predicted that weaker implicit and explicit bias against interracial couples would be observed among those who had been involved in interracial romantic relationships (Hypothesis 2) ${ }^{1}$ and those with more contact with interracial couples (Hypothesis 3). We also explored the relation between self-reported exposure to interracial couples (e.g., in one's community) and bias against interracial couples — though we made no predictions.

\section{Method}

\section{Preregistration}

Our preregistered design and analysis plans are available online (predominately White Sample: https://osf.io/zdfnz/, Black Sample: https://osf.io/xu7pj/, Multiracial Sample: https://osf.io/98a96/). Complete materials and data are also available (https://osf.io/f4y4y/), but only the items referenced in our preregistered analysis plan are reported here.

\section{Materials and Procedure}

Respondents volunteered online through the Project Implicit research pool website (https://implicit.harvard.edu/implicit/Registration) and were randomly assigned into this study from among all the studies they qualified for based on the demographic information provided when their account was created. Respondents provided informed consent before moving on to report demographics and complete all study measures (presented in randomized order). The university’s Institutional Review Board approved all materials and procedures.

Indirect measure. We created a new version of the Implicit Association Test (IAT; Greenwald, McGhee, \& Schwartz, 1998) to assess implicit bias against interracial couples. The IAT indexes associations between pairs of target concepts (same-race and interracial couples)

\footnotetext{
${ }^{1}$ Hypothesis 2 was not applied to our Multiracial Sample.
} 
and attribute concepts (good and bad) by measuring the speed with which respondents classify stimuli from each category. IAT stimuli consisted of color images of heterosexual Black and White same-race couples, color images of heterosexual Black-White interracial couples (drawn from Skinner \& Hudac, 2017), positive words, and negative words. In two initial blocks (20 trials each), respondents used two computer keys to practice discriminating target and attribute stimuli. Next, respondents completed two critical blocks (20 and 40 trials) in which these tasks were combined, classifying items from one target-attribute pairing with one response key (e.g., interracial + good) and classifying items from the alternative target-attribute pairing with another response key (e.g., same-race + bad). After practice reversing the key assignments for attribute categories (28 trials), respondents completed two additional critical blocks (20 and 40 trials, respectively) with the alternative target-attribute pairings (e.g., interracial + bad; same-race + good) from the initial critical blocks. We refer to blocks in which pairings are consistent with bias against interracial couples as congruent (i.e., interracial + bad; same-race + good), and blocks in which pairings are consistent with bias against same-races couples as incongruent. Order of target-attribute pairings was counterbalanced across respondents. A red "X" appeared on the screen following incorrect categorizations and respondents were required to correct the error before moving to the next trial.

\section{Direct measures (self-report).}

Explicit bias towards interracial couples. Respondents reported (a) their feelings toward Black-White interracial couples and same-race couples in two separate items (11-point scales ranging from "extremely warm" to "extremely cold"), and (b) their relative preference for samerace couples (Black and White) relative to Black-White interracial couples (7-point scale ranging from "strongly prefer same-race couples over interracial couples" to "strongly prefer interracial 
couples over same-race couples"). To create a composite measure, we first standardized $(S D=1)$ the difference between ratings on the two feeling thermometers and ratings on the relative measure. Because we were interested in examining whether bias differed from zero, we set the standard deviation to 1 , but retained the natural zero point (rather than centering at the mean). We then averaged these two standardized scores (positive values indicate preference for samerace couples).

Experience with interracial romance (predominately White and Black Samples only). Respondents indicated whether they had ever had "a romantic or sexual encounter with someone outside of [their] racial or ethnic group." Respondents who indicated "yes" to this item were coded as having experience with interracial romance (-0.5 = "yes"; $0.5=$ "no").

Contact with interracial couples. Respondents estimated the (a) number of couples they know that are Black-White interracial, (b) proportion of couples they know that are Black-White interracial, and (c) amount of time spent with Black-White interracial couples in the last three months. Scores on these measures were standardized ( $z$-scored) and averaged to create an index of contact with Black-White interracial couples (higher scores indicate more contact).

Exposure to interracial couples. Respondents self-reported the (a) percentage of couples in their city or town that are Black-White interracial and (b) frequency (number of weeks in the last 3 months) with which they saw interracial couples out in public (e.g., at the grocery store). Scores on these measures were standardized ( $z$-scored) and averaged to create an index of exposure to Black-White interracial couples (higher scores indicate more exposure).

Parent race items. Respondents in the Multiracial Sample were asked whether their parents are the same race, and how much of the participant's life their parents were together as a couple (none, one-quarter, half, three-quarters, or all). 
Demographics. Respondents provided information about their sex, age, race, ethnicity, education, political identity, and other demographic information (all variables and response options are posted online).

\section{Predominately White Sample}

Respondents. Bias against interracial couples in the U.S. has primarily been assessed among White individuals (Skinner \& Hudac, 2017). Based on the demographics of our previous Project Implicit samples, we anticipated that a target sample of 1,100 would likely produce a large enough sample of White respondents $(N=785)$ to have $80 \%$ power to detect a "small" (Cohen, 1988) correlation of $r=.10$ (using a two-tailed test and an alpha of .05). The final sample used for analysis consisted of 1,217 adults, who self-identified as White (77\%), Asian (6\%), Multiracial (6\%), or another race $(11 \%)$ - though none self-identified as Black.

Participant demographics for all samples are presented in Table 1.

Table 1

Participant Demographics for Each Sample

\begin{tabular}{lccccc}
\hline & $\begin{array}{c}\text { Mean (SD) } \\
\text { age in years }\end{array}$ & $\begin{array}{c}\text { Mean (SD) } \\
\text { political } \\
\text { orientation }\end{array}$ & $\%$ women & $\begin{array}{c}\text { \% with a } \\
\text { Bachelor's } \\
\text { Degree or } \\
\text { higher }\end{array}$ & $\begin{array}{c}\% \text { with } \\
\text { interracial } \\
\text { romance } \\
\text { experience }\end{array}$ \\
\hline Predominately White Sample & 35.42 & $0.75(1.71)$ & $68 \%$ & $59 \%$ & $61 \%$ \\
Black Sample & $(15.14)$ & & & & $51 \%$ \\
Multiracial Sample & 35.10 & $0.69(1.45)$ & $75 \%$ & $50 \%$ & $87 \%$ \\
& $(13.62)$ & $0.96(1.48)$ & $68 \%$ & $50 \%$ \\
\hline
\end{tabular}

Note. Political orientation ranges from -3 (Strongly Conservative) to +3 (Strongly Liberal). 


\section{Results}

Analysis strategy. Of our original sample, $2.35 \%$ of respondents were excluded from IAT analysis because they responded in less than $300 \mathrm{~ms}$ on more than $10 \%$ of trials, responded incorrectly on more than $30 \%$ of trials, or responded incorrectly on more than $40 \%$ of trials in either set of IAT critical blocks (preregistered exclusion criteria). IAT data were analyzed using multilevel modeling. Although calculation of standardized effect sizes for each participant, known as $D$-scores ${ }^{2}$ (Greenwald, Nosek, \& Banaji, 2003), is the most common approach to scoring IAT measures, it lowers statistical power and can remove meaningful variance (e.g., Van Bavel \& Cunningham, 2009). Multilevel modeling reduces Type I error rates by incorporating and adjusting for each participant's reaction time on each individual trial using random effects of both respondents and stimuli (Judd, Westfall, \& Kenny, 2012).

Consistent with our preregistration, reaction times more than 1.5 times the interquartile range above the third quartile or below the first quartile were identified as outliers and removed (Tukey, 1977). This approach generally produces a non-skewed distribution of reaction times, but for these data the distribution remained positively skewed. To accommodate the nonnormally distributed data, we used the SAS Studio 3.4 PROC GLIMMIX procedure with an Inverse Gaussian distribution and an identity link to implement multilevel models with random effects for both respondents and IAT stimuli, consistent with the procedures outlined by Wolsiefer, Westfall, and Judd (2017). We also excluded trials in which response latencies were extremely fast $(<400 \mathrm{~ms})^{3}$, consistent with the approach used by Wolsiefer and colleagues (2017). Of the original set of responses $9.76 \%$ were identified as outliers and removed.

\footnotetext{
${ }^{2} D$-score analyses for all samples are reported in supplemental materials.

${ }^{3}$ Strictly adhering to our preregistered criteria for outlier elimination (lower bound $0 \mathrm{~ms}$ ) resulted in a model that failed to converge.
} 
IAT block $(-0.5=$ congruent block; $0.5=$ incongruent block $)$ was the sole predictor in the first model. The second model included interactions between IAT block and (a) experience with interracial romance, (b) contact with interracial couples, and (c) exposure to interracial couples (e.g., in one's community). Random effects of IAT block across respondents and stimuli were also included when possible. SAS code for all models is provided in the supplement. There is presently no consensus on how to appropriately calculate effect sizes in multilevel models (Peugh, 2010), therefore these analyses are accompanied by exact $p$-values and $95 \%$ confidence intervals only. Degrees of freedom vary across analyses due to missing data.

Implicit bias against interracial couples. The predominately White Sample was significantly faster in the congruent block than the incongruent block of the IAT $\left(M_{d i f f}=82.92\right.$, $S E=4.80)$, indicating bias against interracial couples, $t(90)=17.26, p<.001,95 \%$ CI $[73.38$, 92.47]. See Figure 1 for results relative to the Black and Multiracial Samples.

Respondents in the predominately White Sample with no experience (vs. previous experience) with interracial romance were significantly more biased against interracial couples $(b=57.49, S E=8.52), t(118,000)=6.75, p<.001,95 \%$ CI $[40.79,74.18]$. More self-reported contact with interracial couples was associated with lower levels of bias against interracial couples $(b=-15.62, S E=5.71), t(118,000)=-2.74, p=.006,95 \%$ CI $[-26.81,-4.44]^{4}$. Selfreported exposure to interracial couples did not significantly predict bias against them $(b=$ $-6.69, S E=5.87), t(118,000)=-1.14, p=.254,95 \%$ CI $[-18.20,4.82]$. See Supplemental Material for additional analyses probing all reported interactions.

Explicit bias against interracial couples. Results of a $t$-test (see Figure 2) indicated that the predominately White Sample showed a very small but significant explicit bias against

\footnotetext{
${ }^{4} D$-score analysis indicated that self-reported contact was not a statistically significant predictor $(p=.054)$.
} 
interracial couples $(M=0.09, S E=0.02), t(1,193)=3.62, p<.001, d=.10,95 \%$ CI $[0.04,0.13]$.

There was a small but significant correlation between scores on the direct and indirect ( $D$-scores) measures, $r(1,124)=.21, p<.001$.

We used linear regression to examine the effect of previous experience with interracial romance, as well as self-reported contact with and exposure to interracial couples, on explicit bias. Respondents in the predominately White Sample with no experience with interracial romance showed higher levels of bias against interracial couples $(b=0.29, S E=0.05), t(1,147)=$ $5.90, p<.001,95 \%$ CI $[0.20,0.39], R_{\text {partial }}^{2}=.029$. More self-reported contact with interracial couples was associated with reduced explicit bias against them $(b=-0.12, S E=0.03), t(1,147)=$ $-3.66, p<.001,95 \%$ CI $[-0.19,-0.06], R_{\text {partial }}^{2}=.011$. Explicit bias did not significantly vary as a function of self-reported exposure to interracial couples $(b=-0.01, S E=0.03), t(1,147)=$ $-0.20, p=.841,95 \%$ CI $[-0.07,0.06], R_{\text {partial }}^{2}=.000$.

All analyses were replicated excluding all non-White respondents and statistical conclusions were identical.

\section{Black Sample}

Respondents. We set a target $N$ of 250 complete responses for our Black Sample because, for typical effect sizes observed in social and personality psychology, correlations tend to stabilize around 250 (Schönbrodt \& Perugini, 2013). The final sample used for analysis consisted of 293 adults who self-identified as Black or African American.

\section{Results}

Our analytic approach was identical to that used in our predominately White Sample. Implicit bias against interracial couples. Of our original sample, $4 \%$ of respondents failed to meet our preregistered inclusion criteria for the IAT and $10.18 \%$ of responses were 
identified as outliers and removed (see Analysis Strategy section for details). Black respondents were significantly faster in the congruent block than the incongruent block of the IAT $\left(M_{\text {diff }}=\right.$ 138.72, $S E=10.58$; see Figure 1), consistent with implicit bias against interracial couples, $t(90)$ $=13.11, p<.001,95 \%$ CI $[117.69,159.75]$.

Black respondents with no experience with interracial romance were significantly more biased against interracial couples $(b=92.16, S E=20.97), t(26,456)=4.39, p<.001,95 \% \mathrm{CI}$ [51.04, 133.27]. More self-reported contact with interracial couples was associated with reduced bias against them $(b=-38.18, S E=12.61), t(26,456)=-3.03, p=.003,95 \%$ CI $[-62.90$, -13.46]. Self-reported exposure to interracial couples did not significantly predict bias against them $(b=8.82, S E=14.17), t(26,456)=0.62, p=.534,95 \%$ CI $[-18.95,36.60]$.

Explicit bias against interracial couples. Results of a $t$-test indicated that Black respondents also showed explicit bias against interracial couples, $(M=0.30, S E=0.04$; see Figure 2$), t(288)=6.77, p<.001, d=.40,95 \%$ CI $[0.21,0.39]$. There was a small but significant correlation between direct and indirect ( $D$-scores) measures of bias, $r(260)=.15, p=$ .011.

A regression model using our three self-reported individual difference variables to predict explicit bias against interracial couples in the Black Sample, indicated that bias did not significantly vary as a function of previous experience with interracial romance $(b=0.13, S E=$ $0.10), t(269)=1.32, p=.188,95 \%$ CI $[-0.06,0.32], R_{\text {partial }}^{2}=.006$. More contact with interracial couples was associated with lower levels of explicit bias against them $(b=-0.18, S E$ $=0.06), t(269)=-2.85, p=.005,95 \% \mathrm{CI}[-0.31,0.06], R_{\text {partial }}^{2}=.029$. Exposure to interracial couples did not significantly predict explicit bias against them $(b=0.02, S E=0.07), t(269)=$ $0.31, p=.755,95 \% \mathrm{CI}[-0.11,0.15], r_{\text {partial }}^{2}=.000$. 


\section{Multiracial Sample}

Respondents. We set a target $N$ of 250 complete responses, based on the same rationale used to set our Black Sample size. The final sample used for analysis consisted of 284 selfidentified Multiracial adults.

\section{Results}

Given that multiracial individuals have few romantic options that could not be construed as interracial, we did not test for the effects of interracial romance experience in this sample. Our analytic approach was identical to that used in the previous samples in all other respects.

Implicit bias against interracial couples. Of our original sample, $4.25 \%$ failed to meet our preregistered IAT inclusion criteria and $10.17 \%$ of responses were identified as outliers and removed (see Analysis Strategy section for details). Multiracial respondents were not significantly faster in the congruent block than the incongruent block of the IAT $\left(M_{\text {diff }}=13.50\right.$, $S E=8.07 ;$ see Figure 1$), t(90)=1.67, p=.098,95 \%$ CI $[-2.54,29.54]$.

Multiracial respondents who self-reported more contact with interracial couples were significantly less biased against them $(b=-52.82, S E=9.72), t(27,010)=-5.43, p<.001,95 \%$ CI $[-71.88,-33.76]$. Self-reported exposure to interracial couples did not predict bias against them $(b=11.67, S E=10.53), t(27,010)=1.11, p=.268,95 \%$ CI $[-8.97,32.31]$. 


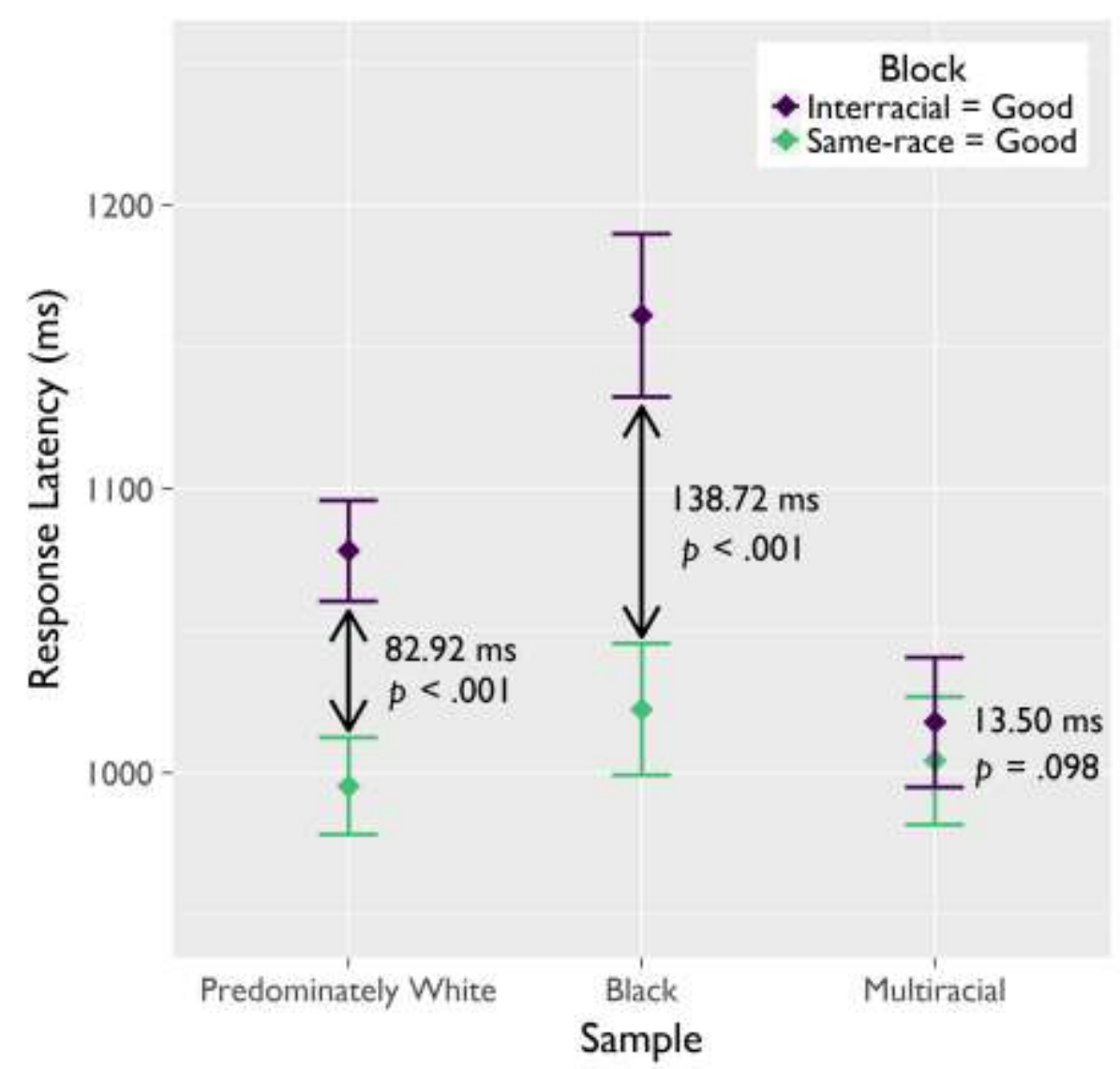

Figure 1. Model predicted response latency (in milliseconds) for IAT critical blocks for the predominately White Sample, Black Sample, and Multiracial Sample. Faster responding in the congruent block is consistent with an implicit preference for same-race couples over interracial couples. Error bars are 95\% CIs.

We also tested whether having parents of different races (an interracial couple) predicts implicit bias against interracial couples, thus the interaction between parent race and IAT block was added to the model ${ }^{5}$. Controlling for self-reported contact with and exposure to interracial couples (which were both significant predictors in this model), not having interracial parents predicted increased bias against interracial $\operatorname{couples}^{6}(b=42.23, S E=8.73), t(27,255)=4.84, p<$

\footnotetext{
${ }^{5}$ Models including parent race would not converge if IAT block was permitted to vary across respondents, thus the random effect of IAT block across respondents was removed from this model.

${ }^{6} D$-score analysis indicated that having interracial parents was not a significant predictor $(p=.054)$ of bias.
} 
$.001,95 \%$ CI $[25.12,59.34]$. Respondents with parents of different races were not significantly faster to make categorizations in the congruent block, relative to the incongruent block $\left(M_{\text {diff }}=\right.$ $6.96, S E=6.07), t(27,255)=1.15, p=.251,95 \%$ CI $[-4.93,18.85]$. In contrast, respondents with parents of the same race were faster to make categorizations in the congruent block, relative to the incongruent block $\left(M_{\text {diff }}=-35.27, S E=7.32\right), t(27,255)=-4.82, p<.001,95 \% \mathrm{CI}$ $[-49.63,-20.92]$. Moreover, this effect was not moderated by the percentage of the participant's life that their parents remained together as a couple, $t(27,252)=0.05, p=.961,95 \%$ CI $[-10.34$, 10.87].

Explicit bias against interracial couples. Results of a $t$-test indicated that Multiracial respondents showed significant levels of explicit bias in favor of interracial couples, $(M=-0.20$, $S E=0.05$; see Figure 2$), t(281)=-4.18, p<.001, d=.25,95 \%$ CI $[-0.30,-0.11]$. There was a small but significant positive correlation between scores on the direct measure and the indirect measure $(D$-scores $), r(262)=.17, p=.007$.

We used linear regression to examine whether our two self-reported individual difference variables predicted explicit bias against interracial couples in the Multiracial Sample. Less contact with interracial couples was associated with more bias against them $(b=-0.23, S E=$ $0.06), t(273)=-3.65, p<.001,95 \%$ CI $[-0.36,-0.11], R^{2}$ partial $=.047$. As exposure to interracial couples increased, bias in favor of interracial couples decreased $(b=0.21, S E=0.07), t(273)=$ $3.06, p=.003,95 \%$ CI $[0.07,0.34], R_{\text {partial }}^{2}=.033$. 


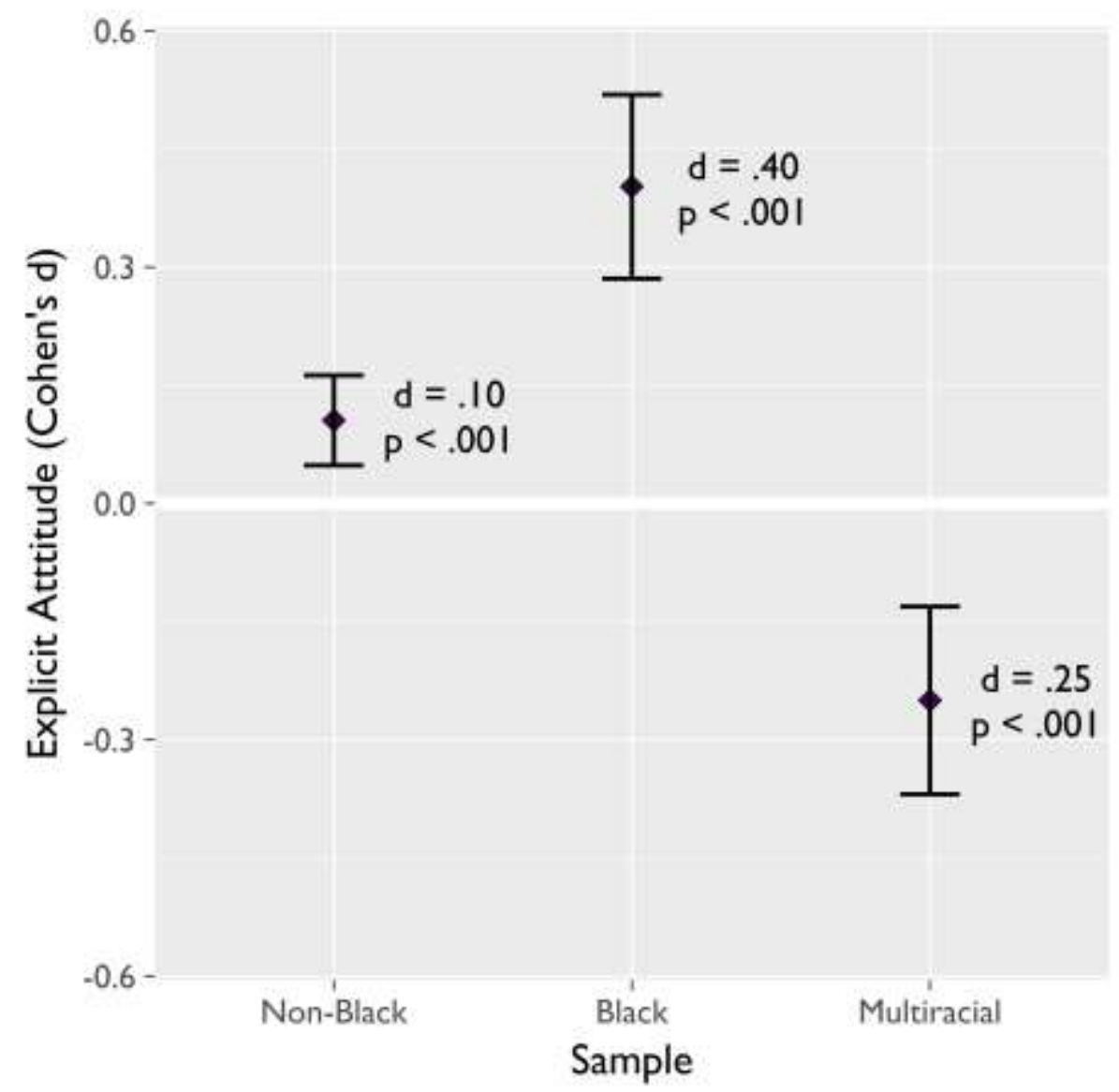

Figure 2. Mean scores (with tests against zero) for the predominately White Sample, Black Sample, and Multiracial Sample on the direct measure. Error bars are 95\% CIs. Positive values indicate preference for same-race couples over interracial couples. Negative values indicate preference for interracial couples over same-race couples.

We also tested whether having parents of different races predicted explicit bias against interracial couples. Controlling for contact with and exposure to interracial couples (which both remained significant predictors), having interracial parents did not predict explicit bias against interracial couples, $t(272)=0.79, p=.428,95 \% \mathrm{CI}[-0.12,0.27]$. This effect was not qualified by the proportion of the participant's life that parents remained a couple, $t(270)=-0.49, p=$ $.623,95 \%$ CI $[-0.15,0.09]$. 


\section{Combined Analyses}

To investigate whether biases significantly varied across samples we conducted combined analyses of the data from all three samples. With regard to the IAT, Bonferroni corrected pairwise comparisons indicated that the reaction speed difference in the Multiracial Sample was smaller than the reaction speed difference in the predominately White Sample, $t(178,000)=4.46, p<.001$. The reaction speed difference was also smaller in the Multiracial Sample relative to the Black Sample, $t(178,000)=6.29, p<.001$. In addition, the reaction speed difference in the predominately White Sample was smaller than the reaction speed difference in the Black sample, $t(178,000)=3.58, p=.001$. With regards to explicit bias, Bonferroni corrected pairwise comparisons indicated that all samples also significantly differed from one another ( $p$ s $<.001)$.

\section{Discussion}

Consistent with our preregistered hypotheses, we found evidence of bias against interracial couples in large samples of predominately White respondents and Black respondents from across the U.S. Moreover, our combined analyses indicated that the Multiracial Sample showed significantly less implicit and explicit bias than the other two samples. Although not predicted, the combined analyses indicated that there was less bias against interracial couples in our predominately White Sample relative to our Black Sample. These findings are consistent with previous work indicating that Black women (who were considerably overrepresented in our sample) are less favorable toward interracial romance than White women (Paset \& Taylor, 1991)_in part because interracial romance often limits the romantic prospects available to Black women (e.g., Childs, 2005b; Crowder \& Tolnay, 2000). Next, we summarize our results for the hypothesized moderators of bias against interracial couples. 


\section{Moderators of Bias Against Interracial Couples}

Experience with interracial romance. As predicted, we found that those who were currently (or had previously been) involved in interracial romantic relationships had more favorable attitudes towards interracial couples. Implicit bias against interracial couples was lower among both predominately White and Black respondents with a history of interracial romance. In the predominately White Sample (but not the Black Sample), those with interracial romance experience also showed less explicit bias against interracial couples than those without interracial romance experience.

Contact with interracial couples. Consistent with our hypothesis about contact (e.g., Allport, 1954) with interracial couples, respondents from all three samples who reported more contact with interracial couples showed reduced implicit and explicit biases against them.

Exposure to interracial couples. For Multiracial identified respondents, we found evidence that increased exposure to interracial couples was associated with increased explicit bias against them. This suggests that among Multiracial identified respondents, seeing interracial couples in ones' community may, for example, result in a sense of betrayal (Childs, 2005a). In other words, seeing Black people in romantic relationships with White people might give the impression that they are disloyal to the racial minority group — resulting in negative associations with interracial couples. Replicating this finding, and testing for possible mechanisms (e.g., perceived betrayal), will be important in developing our understanding of the factors that shape attitudes toward interracial couples among racial minority group members.

\section{The Unique Case of Multiracial Respondents}

We hypothesized that flexible social identities (e.g., Daniel, 2002; Gaither et al., 2014) and intimate contact with interracial couples would mitigate bias against interracial couples 
among Multiracial respondents. Consistent with this prediction, Multiracial respondents were not significantly faster in the congruent block than the incongruent block of the IAT. Multiracial respondents with parents of the same race showed more implicit bias against interracial couples than those who reported having parents of different races (58\% of our sample). Moreover, Multiracial respondents with extensive self-reported contact with interracial couples actually showed evidence of implicit favoritism for interracial couples. Critically, we observed an effect of self-reported contact with interracial couples even after controlling for whether respondents' parents were interracial, which suggests that Multiracial respondents' more favorable attitudes toward interracial couples cannot be entirely explained by familial contact.

Multiracial people may have few romantic options that would not qualify as interracial (e.g., a relationship with another individual with the same mixed-race heritage). In the Multiracial Sample interracial dating was the predominate experience; over $87 \%$ of respondents indicated that they had dated interracially. Thus, the attitudes of Multiracial identified respondents may also reflect their own relationship prospects and interracial romantic history. Future studies will be essential for identifying the factors underlying Multiracial respondents relative lack of bias against interracial couples.

It is worth noting that our samples were based on racial self-identification (vs. ancestry). Most Black-White biracial adults in the U.S. self-identify as "biracial," but there is a portion of this group that self-identifies as Black (Khanna \& Johnson, 2010). Thus, some portion of the respondents in our Black Sample may have mixed-race ancestry_but self-identify as Black — and only those who self-identify as Multiracial were included in the Multiracial Sample. It is possible that those with mixed-race ancestry who do not self-identify as Multiracial have more bias against interracial couples_-future research should investigate this possibility. 


\section{Broader Implications}

Moving beyond attitudes toward interracial couples specifically, these findings contribute to a growing body of work demonstrating the importance of investigating attitudes and biases against meaningful social units—such as families and couples (Kille \& Tse, 2017; Skinner \& Hudac, 2017). Future research should examine the extent to which these attitudes overlap with known racial biases versus represent unique social attitudes. Moreover, additional research is needed to determine whether the biases against Black-White interracial couples observed in the current research generalize to interracial couples more broadly and whether bias against interracial couples varies as a function of couple composition (e.g., Black-White vs. WhiteAsian).

Although polling data indicates that most in the U.S. approve of interracial marriage, the current findings suggest that they still harbor biases against interracial couples. So, what implications does this have for interracial couples? Previous literature suggests that implicit and explicit biases predict distinct behavioral expressions. Explicit biases predict deliberative judgments and behaviors, whereas implicit biases predict spontaneous reflexive reactions (e.g., Dovidio, Kawakami, \& Gaertner, 2002). Thus, among those that express explicit biases against interracial couples we might expect more overt discrimination against interracial couples. For example, a Louisiana justice of the peace refused to marry interracial couples (Associated Press, 2009), a Kentucky church prohibits interracial couples from joining the congregation (Estep, 2011), and a Mississippi landlord evicted a husband and wife explicitly because they were different races (Mitchell, 2016). By contrast, implicit biases against interracial couples might better predict spontaneous decisions, such as whether to pull over and help a couple stranded on the side of the road, approve a loan application, or select tenants. By highlighting existing biases 
against interracial couples, we open the door for future research that can begin to examine the origins of these biases and their consequences they have for interracial couples. 


\section{References}

Allport, G. W. (1954). The nature of prejudice. Cambridge, MA: Addison-Wesley.

Associated Press of New Orleans (2009, October 16). US mixed race couple denied marriage license. The Guardian. Retrieved from: theguardian.com

Childs, E. C. (2005a). Navigating interracial borders: Black-White couples and their social worlds. Rutgers University Press.

Childs, E. C. (2005b). Looking behind the stereotypes of the "angry black woman" an exploration of Black women's responses to interracial relationships. Gender \& Society, 19, 544-561. https://doi.org/10.1177/0891243205276755

Cohen, J. (1988). Statistical power analysis for the behavioral sciences. New York: Academic Press.

Crisp, R. J., Hutter, R. R., \& Young, B. (2009). When mere exposure leads to less liking: The incremental threat effect in intergroup contexts. British Journal of Psychology, 100, 133149. https://doi.org/10.1348/000712608X318635

Crowder, K. D., \& Tolnay, S. E. (2000). A new marriage squeeze for black women: The role of racial intermarriage by black men. Journal of Marriage and Family, 62, 792-807. https://doi.org/10.1111/j.1741-3737.2000.00792.x

Daniel, G. R. (2002). More than Black? Multiracial identity and the new racial order. Temple University Press.

De Houwer, J. (2006). What are implicit measures and why are we using them. In R. W. Wiers \& A. W. Stacy (Eds.), The handbook of implicit cognition and addiction (pp. 11-28). Thousand Oaks, CA: Sage. 
Dovidio, J. F., Kawakami, K., \& Gaertner, S. L. (2002). Implicit and explicit prejudice and interracial interaction. Journal of Personality and Social Psychology, 82, 62-68. https://doi.org/10.1037//0022-3514.82.1.62

Estep, B. (2011, November 30). Pike church takes stand against interracial couples. Lexington Herald Leader. Retrieved from: kentucky.com

Fitzpatrick, M. (2015, December 31). 2015 was a huge year for interracial relationships on TV. Fusion. Retrieved from: fusion.net

Foeman, A. K., \& Nance, T. (1999). From miscegenation to multiculturalism. Perceptions and stages of interracial relationship development. Journal of Black Studies, 29, 540-557. https://doi.org/10.1177/002193479902900405

Gaither, S. E., Chen, E. E., Corriveau, K. H., Harris, P. L., Ambady, N., \& Sommers, S. R. (2014). Monoracial and biracial children: Effects of racial identity salience on social learning and social preferences. Child Development, 85, 2299-2316. https://doi.org/10.1111/cdev.12266

Greenwald, A. G., \& Banaji, M. R. (1995). Implicit social cognition: Attitudes, self-esteem, and stereotypes. Psychological Review, 102, 4-27. https://doi.org/10.1037/0033295X.102.1.4

Greenwald, A. G., McGhee, D. E., \& Schwartz, J. L. (1998). Measuring individual differences in implicit cognition: The implicit association test. Journal of Personality and Social Psychology, 74, 1464-1480. https://doi.org/10.1037/0022-3514.74.6.1464

Greenwald, A. G., Nosek, B. A., \& Banaji, M. R. (2003). Understanding and using the implicit association test: I. An improved scoring algorithm. Journal of Personality and Social Psychology, 85, 197-216. https://doi.org/10.1037/0022-3514.85.2.197 
Grush, J. E. (1976). Attitude formation and mere exposure phenomena: A nonartifactual explanation of empirical findings. Journal of Personality and Social Psychology, 33, 281-290. https://doi.org/10.1037/0022-3514.33.3.281

Hayes, A. (2012, February 16). Study: Interracial marriage, acceptance growing. CNN. Retrieved from: cnn.com

Judd, C. M., Westfall, J., \& Kenny, D. A. (2012). Treating stimuli as a random factor in social psychology: a new and comprehensive solution to a pervasive but largely ignored problem. Journal of Personality and Social Psychology, 103, 54-69. https://doi.org/10.1037/a0028347

Khanna, N., \& Johnson, C. (2010). Passing as Black: Racial identity work among biracial Americans. Social Psychology Quarterly, 73, 380-397. https://doi.org/10.1177/0190272510389014

Kille, D. R., \& Tse, C. T. (2017). Whose family fits? Categorization and evaluation of same-sex and cross-race-parent families. Group Processes \& Intergroup Relations, 20, 109-124. https://doi.org/10.1177/1368430215595106

Lienemann, B. A., \& Stopp, H. T. (2013). The association between media exposure of interracial relationships and attitudes toward interracial relationships. Journal of Applied Social Psychology, 43, 398-415. https://doi.org/10.1111/jasp.12037

Loving v. Virginia (1967). 388 U.S. 1.

Mitchell, J. (2016, April 3). Mississippi interracial couple evicted from RV park. USA Today. Retrieved from: usatoday.com

Mullins, D. (2014, April 11). Advertising features more gay, interracial families. Aljazeera America. Retrieved from: America.aljazeera.com 
Newport, F. (2013, July). In U.S., 87\% approve of Black-White marriage, vs. 4\% in 1958. Gallup News. Retrieved from: news.gallup.com

Paset, P. S., \& Taylor, R. D. (1991). Black and White women's attitudes toward interracial marriage. Psychological Reports, 69, 753-754. https://doi.org/10.2466/pr0.1991.69.3.753

Pettigrew, T. F., \& Tropp, L. R. (2006). A meta-analytic test of intergroup contact theory. Journal of Personality and Social Psychology, 90, 751-783. https://doi.org/10.1037/0022-3514.90.5.751

Peugh, J. L. (2010). A practical guide to multilevel modeling. Journal of School Psychology, 48, 85-112. https://doi.org/10.1016/j.jsp.2009.09.002

R. L. (2016, December 8). "Loving" and "A United Kingdom.” The Economist. Retrieved from: economist.com

Rae, J. R., Newheiser, A.-K., \& Olson, K. R. (2015). Exposure to racial out-groups and implicit race bias in the United States. Social Psychological and Personality Science, 6, 535-543. https://doi.org/10.1177/1948550614567357

Roccas, S., \& Brewer, M. B. (2002). Social identity complexity. Personality and Social Psychology Review, 6, 88-106. https://doi.org/10.1207/S15327957PSPR0602_01

Schönbrodt, F. D., \& Perugini, M. (2013). At what sample size do correlations stabilize? Journal of Research in Personality, 47, 609-612. https://doi.org/10.1016/j.jrp.2013.05.009

Sherif, M. (1966). In common predicament: Social psychology of intergroup conflict and cooperation. Boston: Houghton-Mifflin.

Shook, N. J., \& Fazio, R. H. (2008). Interracial roommate relationships: An experimental field test of the contact hypothesis. Psychological Science, 19, 717-723. https://doi.org/10.1111/j.1467-9280.2008.02147.x. 
Skinner, A. L., \& Hudac, C. M. (2017). “Yuck, you disgust me!” Affective bias against interracial couples. Journal of Experimental Social Psychology, 68, 68-77. https://doi.org/10.1016/j.jesp.2016.05.008

Tajfel, H. (1978). Social categorization, social identity and social comparison. In H. Tajfel (Ed.), Differentiation between social groups: Studies in social psychology of intergroup relations (pp. 61-76) London: Academic Press.

Tukey, J. W. (1977). Exploratory data analysis. Reading, MA: Addison-Wesley.

Turner, R. N., Hewstone, M., \& Voci, A. (2007). Reducing explicit and implicit outgroup prejudice via direct and extended contact: The mediating role of self-disclosure and intergroup anxiety. Journal of Personality and Social Psychology, 93, 369-88. https://doi.org/10.1037/0022-3514.93.3.369

Turner, J. C., Hogg, M. A., Oakes, P. J., Reicher, S. D., \& Wetherell, M. S. (1987). Rediscovering the social group: A self-categorization theory. Cambridge, MA: Basil Blackwell.

Van Bavel, J. J., \& Cunningham, W. A. (2009). Self-categorization with a novel mixed-race group moderates automatic social and racial biases. Personality \& Social Psychology Bulletin, 35, 321-35. https://doi.org/10.1177/0146167208327743

Wang, W. (2012). The rise of intermarriage: Rates, characteristics vary by race and gender. Pew Research Center: Social and Demographic Trends. Retrieved from: http://www.pewsocialtrends.org/files/2012/02/SDT-Intermarriage-II.pdf

Wolsiefer, K., Westfall, J., \& Judd, C. M. (2017). Modeling stimulus variation in three common implicit attitude tasks. Behavior Research Methods, 49, 1193-1209. https://doi.org/10.3758/s13428-016-0779-0 
Zajonc, R. B. (2001). Mere exposure: A gateway to the subliminal. Current Directions in Psychological Science, 10, 224-228. https://doi.org/10.1111/1467-8721.00154

Zebrowitz, L. A., White, B., \& Wieneke, K. (2008). Mere exposure and racial prejudice:

Exposure to other-race faces increases liking for strangers of that race. Social Cognition, 26, 259-275. https://doi.org/10.1521/soco.2008.26.3.259. 